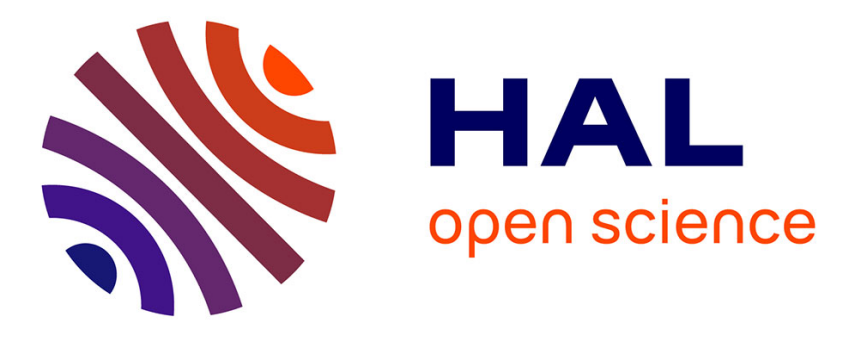

\title{
Host-symbiont specificity in insects: Underpinning mechanisms and evolution
}

Tsubasa Ohbayashi, Peter Mergaert, Yoshitomo Kikuchi

\section{To cite this version:}

Tsubasa Ohbayashi, Peter Mergaert, Yoshitomo Kikuchi. Host-symbiont specificity in insects: Underpinning mechanisms and evolution. Oliver, Kerry M. and Russell, Jacob A. Advances in Insect Physiology, 58, Academic Press, pp.27-62, 2020, Mechanisms Underlying Microbial Symbiosis, 10.1016/bs.aiip.2020.03.002 . hal-03379688

\section{HAL Id: hal-03379688 \\ https://hal.science/hal-03379688}

Submitted on 15 Oct 2021

HAL is a multi-disciplinary open access archive for the deposit and dissemination of scientific research documents, whether they are published or not. The documents may come from teaching and research institutions in France or abroad, or from public or private research centers.
L'archive ouverte pluridisciplinaire HAL, est destinée au dépôt et à la diffusion de documents scientifiques de niveau recherche, publiés ou non, émanant des établissements d'enseignement et de recherche français ou étrangers, des laboratoires publics ou privés. 
1 Host-symbiont specificity in insects: Underpinning mechanisms and evolution

2

3 Tsubasa Ohbayashi ${ }^{1,2}$, Peter Mergaert ${ }^{1}$ and Yoshitomo Kikuchi ${ }^{3,4,5}$

4

5 Affiliations:

$6{ }^{1}$ Institute for Integrative Biology of the Cell, UMR9198, CEA, CNRS, Université Paris-

7 Saclay, 91198 Gif-sur-Yvette, France

$8 \quad{ }^{2}$ Institute for Agro-Environmental Sciences, National Agriculture and Food Research

9 Organization (NARO), 305-8604, Tsukuba, Japan

$10{ }^{3}$ Bioproduction Research Institute, National Institute of Advanced Industrial Science and

11 Technology (AIST), Hokkaido Center, Sapporo 062-8517, Japan

$12{ }^{4}$ Computational Bio Big Data Open Innovation Laboratory (CBBD-OIL), AIST, 062-

138517 Sapporo, Japan

$14{ }^{5}$ Graduate School of Agriculture, Hokkaido University, Sapporo 060-8589, Japan

16 E-mail\&Tel:

17 Tsubasa Ohbayashi: tsubasa.ohbayashi@i2bc.paris-saclay.fr; +33169823791

18 Peter Mergaert: peter.mergaert@ i2bc.paris-saclay.fr; +3316982 3791

19 Yoshitomo Kikuchi: y-kikuchi@aist.go.jp; +81-11-857-8939

20

21 


\section{Abstract}

23 How host organisms evolved and maintain specific mutualisms with microorganisms is

24 a fundamental question that is subject to intensive research. In the large majority of insect mutualistic interactions, the host-microbe specificity is maintained by a "partner fidelity" mechanism, mainly through direct symbiont transmission from mother to

27 offspring. Such a vertical manner of symbiont transmission is remarkably diverse in

28 insects, including ovarial transmission, milk-gland transmission, coprophagy, egg-

29 smearing, and capsule transmission. In contrast to the insect-microbe symbioses, many

30 animals and plants do not vertically transmit their symbionts but acquire symbionts

31 from ambient environments every generation. Sophisticated "partner choice"

32 mechanisms are at play to maintain these mutualisms. This symbiont transmission

33 mode, called horizontal transmission or environmental acquisition, is rarely found in

34 insects, but recent studies have described this type of symbios is in a few insect groups.

35 The symbiosis between the bean bug Riptortus pedestris and its gut symbiont

36 Burkholderia insecticola is one of the model systems that is intensively studied to

37 understand how host-symbiont specificity and mutualistic interactions are maintained in

38 insects with horizontal symbiont transmission. Phylogenetic analyses of symbionts in

39 natural insect populations and bacterial inoculation tests in the laboratory revealed a

40 high degree of specificity in this symbiosis while mutant screening of the symbiotic

41 bacterium, genomics and transcriptomics, and histological observations have identified

42 underpinning genetic and molecular bases. In this chapter, we focus on the symbiont 
43 transmission modes and mechanisms observed in the amazing diversity of microbial

44 symbioses in insects and we highlight how they could have evolved.

$45 \quad(247<250$ words $)$

46

47 Keywords:

48 vertical transmission, environmental acquisition, partner fidelity, partner choice,

49 microbe-microbe competition, Riptortus-Burkholderia symbiosis

50

51

52 


\section{Introduction}

54

55 Many, if not most animals and plants are intimately associated with microorganisms. In

56 these symbioses, the microbial partners contribute to the host fitness via various

57 biological services such as the provision of essential nutrients, protection from

58 antagonists, and degradation of toxins (Engel and Moran, 2013; Itoh et al., 2018b;

59 Kikuchi, 2009). Since environments are filled with enormously diverse microorganisms

60 including not only mutualists but also parasites and pathogens, hosts should winnow out

61 these harmful microbes and selectively acquire the desired partners. To ensure the

62 specific microbial partnership, host organisms have evolved sophisticated mechanisms

63 for symbiont transmission and sorting. In the case of many insects that harbor specific

64 gut or intracellular symbionts, the specific partnership is maintained by the "partner

65 fidelity" mechanism that is based on the from-mother-to-offspring vertical symbiont

66 transmission. The vertical transmission mechanisms in insects are remarkably diverse

67 among taxonomic groups. In other cases, in a few insect groups, in marine invertebrates

68 and in terrestrial plants, symbionts are not vertically transmitted but acquired from the

69 ambient environment every generation (called horizontal transmission or environmental

70 acquisition), wherein "partner choice" mechanisms facilitate the host-microbe

71 specificity (Bright and Bulgheresi, 2010; Sachs et al. 2004). In this section, we will

72 review the amazing diversity of symbiont transmission modes in insects and their

73 underlying mechanisms, highlighting how the host-symbiont specificity is maintained

74 and has evolved in this most diversified terrestrial animal group. 


\section{Vertical transmission}

Insects that feed exclusively on a nutritionally imbalanced diet like plant saps or on indigestible materials like wood commonly harbor specific microbial symbionts that help the hosts to feed and grow on these specific nutritional sources. These symbionts

81 reside in body cavities, gut crypts, or the cytoplasm of specialized cells called mycetocytes or bacteriocytes (Buchner, 1965; Kikuchi, 2009). Symbionts are mostly bacteria, while in some cases yeast-like symbionts, archaea and protist symbionts were

84 also reported (Buchner, 1965; Brune and Dietrich, 2015; Engel and Moran, 2013;

85 Kikuchi, 2009; Ohkuma and Brune, 2010; Sudakaran et al., 2017). The symbiotic microorganisms play a pivotal metabolic role in the insect hosts, such as the production of essential metabolites that are scarce in the diets and that the insect cannot synthesize or the degradation of plant polysaccharides that the insect cannot digest. In such nutritional and digestive symbioses, symbionts are commonly essential for survival,

90 development, and reproduction of the hosts, and therefore, insects show high mortality

91 when symbionts are removed by heat, ethanol and antibiotic treatment (Anbutsu et al., 92 2017; Brake, 1978; Douglas et al., 2001; Fukatsu and Hosokawa, 2002; Hosokawa et

93 al., 2010; Itoh et al., 2016; Kikuchi et al., 2009; Salem et al., 2017; Sangare et al., 2016;

94 Schlein, 1977; Srivastara and Auclair, 1976; Tada et al, 2011). To ensure the

95 acquisition of the obligate partner by the next generation, most insects have evolved 96 mechanisms for strict vertical transmission of the symbionts. It should be noted here 
97 that the vertical manner of symbiont transmission guarantees not only absolute

98 symbiont-acquisition by the offspring but also the host-symbiont specificity from

99 generation to generation. A dramatic consequence of the vertical transmission is that the

100 genomes of the microorganisms are usually strongly eroded and therefore, they are

101 difficult or impossible to culture and manipulate genetically (Kikuchi, 2009;

102 McCutcheon and Moran, 2012; Moran and Bennett, 2014; Moya et al., 2008). To date,

103 various mechanisms for vertical symbiont transmission has been reported in insects.

104 The transmission mechanisms are fundamentally different depending on the symbiont

105 localization pattern, i.e. intracellular or extracellular.

106

107 Vertical transmission of intracellular symbionts

108 Intracellular symbionts are broadly known in diverse groups of insects, including the

109 orders Blattaria, Hemiptera, Coleoptera, Hymenoptera and Diptera, in which symbiont

110 harboring bacteriocytes or mycetocytes form clusters in the insect bodies, called

111 bacteriome or mycetome. Intracellular symbionts are generally transmitted by ovarial

112 transmission, while in some blood-sucking insects of the Diptera, milk-gland

113 transmission has been reported.

114

115 Ovarial transmission

116 In the ovarial transmission mechanism, symbiotic bacteria directly infect the ovary

117 and/or embryo from maternal bacteriocytes (Salem et al., 2015). The detailed infection

118 process has been investigated in the pea aphid Acyrthosiphon pisum (Koga et al., 2012). 
119 At the interface between a maternal bacteriocyte and embryo, the symbiont Buchnera

120 aphidicola is exocytosed from the maternal bacteriocyte, momentarily released into the

121 hemolymph, and then immediately endocytosed by the embryo. Although no detailed

122 observation has been conducted in other insect groups so far, a similar exo- and

123 endocytosis of symbiotic bacteria probably plays an important role in the ovarial

124 transmission mechanisms.

125

126

Milk-gland transmission

127 In blood-sucking insects of the Diptera, such as tsetse flies and bat flies, symbiotic

128 bacteria, Wigglesworthia glossinidia and Aschnera chinzeii, respectively, are

129 transmitted to offspring via the milk-gland, a specific organ that supplies "milk" to

130 larvae (Hosokawa et al., 2012; Attardo et al., 2008). These blood-sucking insects are

131 unique ovoviviparous species and females grow a single larva in a uterus-like organ

132 with milk supplementation which contains the symbiotic bacteria, enabling to transmit

133 the bacteria to the larva.

134

\section{Vertical transmission of extracellular symbionts}

136 Specific extracellular symbionts, most of which are gut symbionts, are reported in

137 termites, stinkbugs, and beetles. The gut symbionts are vertically transmitted either by

138 coprophagy, egg-smearing, or capsule transmission.

139

140 Coprophagy 
141 Termites and wood-feeding cockroaches possess specific gut microbiota in the hindgut,

142 consisting of not only bacteria but also specific protists (Brune and Dietrich, 2015;

143 Ohkuma and Brune, 2010). In these social insects, aposymbiotic individuals such as

144 newly-born hatchlings and newly molted nymphs acquire the specific microbiota by

145 feeding feces excreted from parents or siblings. Such coprophagy is also reported in

146 blood-sucking kissing bug Rhodnius spp., where the symbiont Rhodococcus rhodonii is

147 transmitted through the feeding on feces (Beard et al., 2002). It was suggested that

148 honey bees and ants transmit their specific gut microbiota through coprophagy and/or a

149 specific food-exchange behavior called mouth-to-mouth trophallaxis (Koch et al., 2011;

150 Onchuru et al., 2018; Powell et al., 2014).

152 Egg-smearing

153 Egg-smearing, or egg surface contamination by symbiotic bacteria, has been described

154 in detail in stinkbugs (Bansal et al., 2014; Bistolas et al., 2014; Buchner, 1965; Dasch

155 and Weiss, 1984; Hayashi et al., 2015; Hosokawa et al., 2013; Itoh et al., 2016;

156 Karamipour et al., 2016; Kashkouli et al., 2019a, 2019b, 2019c; Kenyon et al., 2015;

157 Kikuchi et al., 2012, 2009; Miyamoto, 1961; Prado et al., 2009, 2006; Tada et al., 2011;

158 Taylor et al., 2014). Phytophagous species of stinkbugs, particularly members of the

159 infraorder Pentatomomorpha, develop a symbiotic organ composed of rows of crypts,

160 located in the posterior region of the midgut and housing specific extracellular bacterial

161 symbionts (Buchner, 1965; Dasch and Weiss, 1984; Kikuchi et al., 2009; Miyamoto,

162 1961). Most species of the superfamily Pentatomoidea possess gammaproteobacterial 
163 symbionts, which are smeared on the egg surface upon oviposition. In female insects,

164 the last few crypts are bulbous compared with the other crypts and can discharge

165 symbiotic bacteria from the crypt lumen. These crypts are thought to be specialized for 166 housing symbionts for transmission (Hayashi et al., 2015). In the particular case of the

167 stinkbug family Acanthosomatidae however, all crypt entrances are completely sealed

168 in adult insects, making the direct smearing from crypts impossible (Kikuchi et al.,

169 2009). Instead, female insects evolved a novel pair of organs, associated with the female

170 ovipositor and called "lubricating organs". From these sac-like organs, symbionts are

171 smeared on the egg surface during oviposition (Kikuchi et al., 2009). It is still enigmatic

172 when and how the symbiotic bacteria migrate from the gut to the lubricating organ and

173 how the new organ specialized for symbiont transmission evolved in the stinkbug

174 family. In the case of Lagria beetles, antibiotic-producing defensive Burkholderia

175 gladioli symbionts are associated with female accessory glands. They are smeared on

176 the egg surface, protecting host eggs from pathogenic fungi (Kaltenpoth and Florez, 177 2019).

178

179 Capsule transmission

180 Contrary to species of the other Pentatomoidea families, stinkbugs of the family

181 Plataspidae deploy a unique mechanism for vertical transmission, called "capsule

182 transmission" (Buchner, 1965; Fukatsu and Hosokawa, 2002). Together with the egg

183 masses, mother insects oviposit brownish capsules containing the symbiotic bacterium

184 Ishikawaella capsulata and hatchlings acquire the symbiont by sucking up the capsule 
content. Females of the insect develop for capsule production a specific portion in the

186 midgut, located just after the crypt-bearing symbiont-harboring region (Fukatsu and

187 Hosokawa, 2002; Hosokawa et al., 2008; 2007; 2006; 2005). A similar mechanis m,

188 called "jelly transmission", has been reported in another stinkbug family of the

189 Pentatomoidea, the Urostylididae, in which mother insects oviposit eggs with a large

190 amount of a symbiont containing jelly-like matrix (Kaiwa et al., 2014). Hatchlings

191 acquire symbiotic bacteria by consuming the jelly.

In addition to the stinkbug symbioses, another unique type of capsule

193 transmission was discovered in the tortoise leaf beetle Cassida rubiginosa (Salem et al.,

194 2017). The leaf beetle harbors a pectin-degrading symbiont, Candidatus Stammera

195 capleta, inside a pair of sac-like organs associated with the foregut. Female insects

196 deposit a symbiont-containing capsule or "caplet" on the top of each egg and hatchlings

197 acquire the symbiont by consuming the caplet compounds.

198

199 Partner choice in insect-microbe symbiosis with vertical transmission

200 Since insects develop highly sophisticated mechanisms for vertical symbiont

201 transmission as shown above and symbionts generally show phylogenetic congruence

202 with host phylogeny, the transmission mechanisms are commonly thought of as very

203 rigorous without room for parasites and cheaters. However, several studies

204 demonstrated that also partner choice plays a role to maintain the insect-microbe

205 mutualism with vertical transmission. For example, the pea aphid is frequently infected

206 with secondary intracellular symbionts, such as Serratia symbiotica, in addition to the 
207 primary symbiont B. aphidicola (Moran et al., 2005; Oliver et al., 2010). Detailed

208 microscopic observations revealed that Buchnera is selectively transmitted from

209 maternal bacteriocytes to the embryo by the exo-/endocytosis process even when

210 secondary symbionts co-colonize in the bacteriocytes (Koga et al., 2012).

211 Beewolf wasps, that harbor the defensive symbiont Streptomyces philanthi in

212 antennal glands, transmit the symbiont by spreading out gland secretions in their nest,

213 where larvae develop through the pupal stage until adult emergence (Goettler et al.,

214 2007; Kaltenpoth et al., 2010, 2005). The bacteria in the nests provide protection against

215 pathogenic fungi and bacteria by producing different antimicrobial compounds (Kroiss

216 et al., 2010). Interestingly, experimental inoculation of a non-symbiotic actinomycetes

217 bacterium to aposymbiotic adult females revealed that the related bacterium can stably

218 colonize the antennal glands but cannot be secreted and transmitted from the antennae

219 (Kaltenpoth et al., 2014), suggesting that a partner choice mechanism exists in the

220 vertical transmission process. Both cases highlight that partner choice mechanisms

221 reinforce partner fidelity to stabilize long-term, strictly specific insect-microbe

222 symbioses.

224 Horizontal transmission of symbionts in animals and plants

226 Apart from the majority of insect-microbe mutualisms, most animals and also plants do

227 not commonly transmit their symbionts vertically; instead, they acquire specific partners

228 from the ambient environment every generation. Because of the enormous diversity of 
microorganisms in environments, hosts should actively select their symbionts from the

230 environmental microbiota in these symbioses with horizontal symbiont transmission. To

231 efficiently and specifically choose a partner, host organisms develop sophisticated

232 mechanisms for symbiont sorting. Such partner choice mechanisms have been well

233 investigated and described in two model systems: the nitrogen-fixing Rhizobium

234 symbiosis in leguminous plants and the bioluminescent Vibrio symbiosis in the

235 Hawaiian bobtail squid (Nyholm and McFall, 2004; Wang et al., 2018). As mentioned

236 above, the vertically transmitted insect symbionts have strongly reduced genomes,

237 making them unculturable outside their host (Kikuchi, 2009; McCutcheon and Moran,

238 2012; Moran and Bennett, 2014; Moya et al., 2008). Because of their different lifestyles

239 including the free-living state in the environment, the symbionts maintained by

240 horizontal transmission are in contrast culturable and genetically manipulatable. These

241 traits have been very useful to clarify the genetic and molecular bases of the symbiotic

242 associations.

244 The legume-Rhizobium symbiosis

245 The legume-Rhizobium symbiosis is probably the best-characterized symbiotic system

246 from different perspectives, including the understanding of the evolutionary ecology

247 and the molecular mechanisms that govern the symbiosis. In response to nitrogen

248 starvation and the presence of specific compatible rhizobium bacteria in the

249 rhizosphere, legumes will form particular symbiotic organs on their roots, called

250 nodules. The rhizobia are housed in large numbers inside these nodules as intracellular 
251 symbionts and they convert atmospheric nitrogen gas into ammonia, which is used by

252 the plant as a nitrogen source for its growth. The legume-Rhizobium interaction is

253 usually extremely specific and a given Rhizobium strain will interact only with a narrow

254 range of legume species and vice versa. The host-symbiont compatibility is monitored

255 all along the symbiotic process, from the initiation of the interaction over the

256 development and infection of the nodules till the nitrogen fixation in mature nodules.

257 This is achieved by a continuous exchange of signals between the two partners,

258 including plant-derived flavonoids and antimicrobial peptides, and bacterial molecules

259 like lipochitooligosaccharides, extracellular polysaccharides, lipopolysaccharides, type

260 III and type IV secretion effectors and even small RNAs (Poole et al., 2018; Mergaert,

261 2018). Most emblematic among these signals are the rhizobial Nod factors which are

262 produced in the rhizosphere and upon recognition trigger the plant genetic nodulation

263 program. Nod factors are lipochitooligosaccharides, which have a similar structure in all

264 rhizobia but which still differ from each other by the presence of strain-specific

265 chemical modifications (D’Haeze and Holsters, 2002). Nod factor signaling contributes

266 to the specificity of the interaction by the presence of a matching Nod factor receptor

267 complex in the plant. Similarly for the other signals, it is believed that a specific signal-

268 receptor correspondence exists. Moreover, in a mature nodule, the host plants monitor

269 the symbiont's nitrogen-fixation activity. If its performance is not optimal, the hosts

270 control the oxygen supply to the nodule and limit the survival of the symbiont (Kiers et

271 al., 2003). Such sanction mechanisms are thought to be important to prevent the

272 evolution of cheaters and maintain the mutualistic association with horizontal symbiont 
274 mutualism is stabilized by partner choice mechanisms based on signaling cues, avoiding

275 legumes from initiating or completing interactions with incompatible rhizobia, as well

276 as by sanctions applied in established interactions to reduce the costs of maintaining

277 low-quality partners.

278

279 The squid-Vibrio fischeri symbiosis

280 In the case of the squid-Vibrio symbiosis, another type of host-symbiont chemical

281 signaling has been reported (Nyholm and McFall-Ngai, 2004; Visick and Ruby, 2006).

282 Depending on the presence of marine bacteria, squid hatchlings start to produce mucus

283 at ciliated epithelia of the light organ, which traps $V$. fischeri from marine water. $V$.

284 fischeri aggregates on the mucus and out-competes other bacteria, and then migrate into

285 the light organ by passing through a narrow entrance using flagellar motility (Graf and

286 Ruby, 1994; Millikan and Ruby, 2004, 2003; Nyholm et al., 2000). In the duct and crypt

287 of the light organ, a certain concentration of nitric oxide and hypohalous acid is reached

288 further winnowing out contaminating bacteria (Davidson et al., 2004; Small et al., 1999;

289 Weis et al., 1996). Tracheal cytotoxin (TCT), a peptidoglycan fragment derived from $V$.

290 fischeri and LPS are recognized by host receptors and stimulate a morphological

291 alteration of the symbiotic organ (Koropatnick et al., 2004; Nyholm and Graf, 2012),

292 leading to maturation of the light organ and establishment of the symbiosis. V.fischeri-

293 derived outer membrane vesicles (OMVs) are also involved in the morphological

294 alteration and apoptosis of the light organ (Aschtgen et al., 2016a, 2016b). From the 
host side, peptidoglycan recognition proteins (PGRPs) and probably also LPS-binding

296 proteins (LBPs) play important roles for recognition and interaction with the symbiont-

297 derived signals (Chun et al., 2008; Krasity et al., 2011; Nyholm and Graf, 2012; Troll $298 \quad 2009 ; 2010)$.

299

\section{$300 \quad$ Horizontal transmission of symbionts in insects}

301 Recent studies have discovered a few exceptions to the general pattern of vertical

302 symbiont transmission in the insects. These groups of insects acquire the symbionts

303 from the environment (Bright and Bulgheresi, 2010; Salem et al., 2015), like in the

304 legume-Rhizobium and squid-Vibrio symbioses. Among these insect-microbe symbioses

305 with horizontal transmission, the symbiosis between the bean bug Riptortus pedestris

306 and Burkholderia insecticola is a powerful model system (Kaltenpoth and Florez, 2019;

307 Takeshita and Kikuchi, 2017) and it has been well investigated how host-microbe

308 specificity has evolved and is maintained in this insect.

309

310 The bean bug-Burkholderia symbiosis

311 The bean bug $R$. pedestris (Heteroptera: Pentatomomopha: Coreoidea: Alydidae) (Fig.

312 1A) is a serious pest of leguminous crops in India, South-East Asia, China, Korea and

313 Japan (Kikuhara, 2005; Schaefer and Panizzi, 2000). R. pedestris is a hemimetabolous

314 insect and develops to adults via five instar stages in approximately 20 days (Kikuchi

315 and Fukatsu, 2014). As is typical for stinkbugs, R. pedestris possesses numerous crypts

316 at the posterior part of the midgut, in which Burkholderia symbionts are harbored (Fig. 
317 1B-G) (Kikuchi et al., 2005). Burkholderia insecticola strain RPE64 is the type strain

318 for the $R$. pedestris symbionts (Takeshita et al., 2018). The Burkholderia symbiont is

319 beneficial for the host insect: symbiotic insects show a faster development, larger body

320 size, and a higher number of eggs than aposymbiotic insects (Kikuchi et al., 2007;

321 Kikuchi and Fukatsu, 2014). Transcriptomic analyses of the Burkholderia symbiont

322 revealed that the symbiont recycles host's metabolic wastes and provides the host with

323 essential amino acids and vitamins (Ohbayashi et al., 2019a). Among the five instar

324 stages, $R$. pedestris acquires the Burkholderia symbiont from ambient soil mainly in the

$3252^{\text {nd }}$ instar stage (Kikuchi et al., 2011b).

326 The Riptortus-Burkholderia symbiosis is an ideal model to elucidate the

327 molecular bases of host-microbe symbiosis for several reasons. The Burkholderia

328 symbiont is easy to culture in standard bacterial media and to genetically manipulate by

329 standard techniques and tools (Kikuchi and Fukatsu, 2014; Kim et al., 2013; Ohbayashi

330 et al., 2015). The whole genome sequence of the Burkholderia symbiont is available

331 (Shibata et al., 2013; Takeshita et al., 2014). In addition, the bean bug host is easily

332 reared and produces large numbers of offspring in small containers, requiring only dried

333 soybean seeds and distilled water containing ascorbic acid (Kikuchi et al., 2007). The

334 symbiont inoculation method is well established and is based on adding the desired

335 bacteria to the drinking water of the insects (Kikuchi and Fukatsu, 2014). This

336 laboratory inoculation method closely mimics the natural infection process in which the

337 insects acquire the symbionts through drinking or feeding. Although the bean bug

338 genome is not completely sequenced, several sets of transcriptome data are available, 
notably for symbiotic conditions and immune responses (Futahashi et al., 2013;

340 Ohbayashi et al, unpublished data). RNA interference (RNAi) works very well in $R$.

341 pedestris (Futahashi et al., 2011). Contrary to most insect-microbe symbioses where

342 symbionts are essential and aposymbiotic insects have thus a high mortality,

343 aposymbiotic insects of the bean bug show a growth delay but have high survivability

344 (Kikuchi et al., 2007), enabling the genetic and physiological comparisons between

345 aposymbiotic and symbiotic insects. This attractive model system has been used to

346 investigate host-symbiont specificity and how it evolved and is maintained in insect-

347 microbe symbiotic associations with horizontal transmission.

349 The bean bug-Burkholderia symbiosis is highly specific

350 The genus Burkholderia consists of over 100 species and is an ecologically diverse

351 group (Eberl and Vandamme, 2016). Based on genomic phylogeny, the genus is

352 grouped into at least three distinct clades. The first one includes human-, animal-, and

353 plant-pathogens, named the "B. cepacia complex and B. pseudomallei" (BCC\&P) clade

354 (Mahenthiralingam et al., 2005). The second clade consists of many plant growth-

355 promoting rhizobacteria and nodule symbionts of leguminous plants, designated as the

356 "plant-associated beneficial and environmental" (PBE) clade (Suárez-Moreno et al,

357 2012). The third clade mainly consists of environmental species, leaf-nodule symbionts

358 of Rubiaceae plants, and gut symbionts of stinkbugs, and is called the "stinkbug-

359 associated beneficial and environmental" (SBE) clade (Takeshita and Kikuchi, 2017;

360 Peeters et al., 2016). The BCC\&P, PBE, and SBE clades are recently designated as 
different genera called Burkholderia sensu stricto, Paraburkholderia, and Caballeronia,

362 respectively (Beukes et al. 2017). The outgroup of the Burkholderia is the genus

363 Pandoraea, mostly consisting of common soil bacteria.

Analyses of the M4 midgut crypt symbionts in natural populations of $R$.

pedestris systematically demonstrated the colonization by Burkholderia species (Jung and Lee, 2019; Kikuchi et al., 2005; 2011a). These Burkholderia are genetically divers but nearly all of them belong to the SBE clade, although infection with species of the more distant BCC\&P clade was also reported in a particular study of overwintering $R$. pedestris specimens (Jung and Lee, 2019).

As mentioned above, the presence of bacterial symbiont-carrying M4 midgut crypts is very common in the heteropteran infraorder Pentatomomorpha (Kikuchi et al., 2011a). In many species of the superfamilies Coreoidea and Lygaeoidea of the Pentatomomorpha, these crypts are also colonized with SBE Burkholderia (Boucias et al., 2012; Itoh et al., 2014; Garcia et al., 2014; Kikuchi et al., 2011a, 2005; Kuechler et al., 2016; Ohbayashi et al., 2019b; Oliver-Espejel et al., 2011). Nevertheless, other

376 Burkholderia, belonging to the BCC\&P and PBE clades, and even Cupriavidus and 377 Pseudomonas species were occasionally identified in some insect species (Boucias et 378 al., 2012; Garcia et al., 2014; Itoh et al., 2014). However, it should be noted that, except 379 for several SBE Burkholderia isolates from R. pedestris (Kikuchi et al., 2007), Coreus 380 marginatus (Ohbayashi et al., 2019b) and Blissus insularis (Xu et al., 2016), for none of 381 the other identified strains (Burkholderia or other species) the Koch's postulates were verified. These bacteria were not cultured and tested for their capacity to infect and 
383 colonize the crypts of aposymbiotic hosts. Finally, also the M4 midgut crypts in species

384 of the family Largidae of the superfamily Pyrrhocoroidea carry Burkholderia but they

385 belong strictly to the PBE clade (Gordon et al., 2016; Sudakaran et al., 2015; Takeshita 386 et al., 2015).

Together, the inspections of these natural stinkbug samples suggest a very

388 strong or nearly exclusive colonization of the midgut crypts with SBE Burkholderia in

389 the Coreoidea and Lygaeoidea superfamilies and with PBE Burkholderia in the family

390 Largidae of the Pyrrocoroidea. Similarly as what is firmly established for the $R$.

391 pedestris symbionts (Kikuchi et al., 2007), environmental acquisition of the

392 Burkholderia was postulated or demonstrated in all the examined insect species, even if

393 occasional vertical transmission was suggested in some of them (Itoh et al., 2014; Xu et

394 al., 2016). Thus, the infections of the M4 midgut crypts in R. pedestris and its allied

395 stinkbug species should be controlled by efficient partner choice mechanisms that are

396 specific at the broad taxonomic scale of Burkholderia groups. Nevertheless, because of

397 the observed genetic diversity of the symbionts in each insect species, these

398 mechanisms may have a more relaxed specificity at a finer scale of the species and 399 strain level.

$400 \quad$ Two types of laboratory experiments in $R$. pedestris supported these

401 conclusions. In laboratory insects reared on soil, infections with PBE Burkholderia as

402 well as Pandoraea were occasionally identified in the crypts but the overwhelming

403 majority of crypt bacteria belonged to the SBE clade (Itoh et al., 2018a). In a second

404 type of experiments, infection tests of aposymbiotic $R$. pedestris were performed with a 
405 broad range of bacteria in pure culture, including 34 Burkholderia species (13 species of 406 SBE, 12 species of PBE, and 7 species of BCC\&P) and an additional 18 taxonomically

407 diverse non-Burkholderia bacterial species (Itoh et al., 2019). All tested SBE species

408 were very efficiently colonizing the midgut crypts but also most tested PBE species and

409 the tested Pandoraea species, although PBE and Pandoraea species did not fully

410 colonize the M4 crypts. Moreover, the PBE and Pandoraea species enhanced the

411 survival and development of the bean bug similar to SBE species, indicating that these

412 bacteria are not harmful but beneficial to the insect host. On the contrary, the tested

413 BCC\&P Burkholderia species and all other bacterial species, which included other

414 Burkholderiaceae (Ralstonia, Chitinimonas, Cupriavidus) and non-Burkholderiaceae,

415 were unable to establish in the crypts. Thus overall, these laboratory infection

416 experiments using soil or cultured bacteria recapitulated very well the observed natural

417 specificity of $R$. pedestris for SBE Burkholderia, although the specificity seems to be

418 broader in the laboratory than in nature. This then raises the question what the

419 underlying partner choice mechanisms are that determine the symbiont selection in

420 natural and laboratory conditions. This seems to be a particularly fundamental issue in

421 light of the enormous diversity of bacteria in soils (Bahram et al., 2018; Delgado-

422 Baquerizo et al, 2018), suggesting that these mechanisms must be particularly

423 performant.

425 Partner choice mechanisms in Riptortus pedestris

426 The gut constricted region as a partner-choice apparatus 
427 Histological observations and inoculation experiments have revealed that $R$. pedestris 428 develops a marked symbiont sorting organ in the midgut (Ohbayashi et al., 2015). The 429 midgut is separated in five morphologically different sections (Fig. 1C): a swollen first 430 section (M1), a tubular second section (M2), an ovoid-shaped third section (M3), the 431 crypt-bearing fourth section (M4) and in addition, a bulbous part in front of the M4 432 region, called the M4 bulb (M4B). The Burkholderia symbiont partially colonizes the 433 M4B in addition to the M4 crypts. The M1 to M3 sections constitute the digestive 434 regions of the intestine, while the M4B and M4 are symbiotic regions. The junction between M3 and M4B is a remarkably narrow channel which 436 has a diameter close to the dimensions of bacterial cells (Fig. 1C; Fig. 2C). This so437 called "constricted region" is filled with a mucus-like matrix and strictly prevents food 438 flow from M3 to the symbiotic gut sections (Fig. 2A) but this channel also constitutes 439 the gate through which ingested bacteria pass to enter the symbiotic M4 region of the 440 intestine (Fig. 2B and C). However, the constricted region is not a simple open gate 441 allowing any bacteria to pass but it filters them and only bacteria with the right (still 442 unknown) key can pass through. Indeed, co-inoculation tests of a green fluorescence 443 protein (GFP)-labelled B. insecticola and a red fluorescent protein (RFP)-labelled $E$.

444 coli revealed that while E. coli is sorted out by the constricted region, only the 445 Burkholderia symbiont passes and reaches the symbiotic region (Fig. 2D). In addition to 446 E.coli, typical soil bacteria like Pseudomonas putida, Bacillus subtilis, Bradyrhizobium

447 japonicum as well as many other species, also cannot pass through the constricted 448 region and are sorted out (Itoh et al., 2019; Ohbayashi et al., 2015). 
450 superfamilies and the Largidae family, which are commonly associated with

451 Burkholderia, members of the Pentatomoidea, another superfamily of the

452 Pentatomomorpha, possess gammaproteobacterial symbionts in midgut crypts which are

453 maintained by strict vertical transmission (Bansal et al., 2014; Bistolas et al., 2014;

454 Hayashi et al., 2015; Hosokawa et al., 2016, 2013; Itoh et al., 2016; Karamipour et al., 455 2016; Kashkouli et al., 2019a, 2019b, 2019c; Kenyon et al., 2015; Kikuchi et al., 2012;

456 Prado et al, 2009, 2006; Tada et al., 2011; Taylor et al., 2014) using the earlier

457 mentioned mechanisms of egg-smearing, capsule transmission or jelly transmission.

458 Interestingly, the constricted region is broadly conserved, not only in the Burkholderia-

459 associated lygaeoid, coreoid and largid species, but also in the Pentatomoidea (Gordon

460 et al., 2016; Ohbayashi et al., 2015). This strongly suggests that the constricted region

461 evolved in the common ancestor of the stinkbug superfamilies. Thus, even if in the

462 Pentatomoidea, the symbiotic association is mainly maintained by partner fidelity

463 mechanisms, i.e. vertical transmission, partner choice achieved by the constricted region 464 may play a pivotal role in these species too.

466 Corkscrew flagellar motility

467 Although the molecular mechanism underpinning the bacterial sorting in the constricted

468 region remains unclear, a screening for colonization-defect mutants of $B$. insecticola

469 revealed that flagellar motility is a key factor for the symbiont's ability to colonize the 470 M4 crypts (Ohbayashi et al., 2015). Although non-motile mutants reach the M3, they 
471 cannot enter the constricted region and never reach M4B and M4, clearly demonstrating

472 the importance of flagellar motility for passing through the mucus-filled narrow

473 passage. However, this finding raises the question why only the Burkholderia symbiont

474 can pass through the constricted region, in spite of active motility also in the tested $E$.

475 coli, P. putida, and B. subtilis.

476 To date, two types of flagellar motility have been described in bacteria (Jarrel

477 and McBride, 2008): run-and-tumbling motility, described well in bacteria having

478 peritrichous flagella, such as E. coli and Pseudomonas species, but also common in

479 bacteria having polar flagella; and forward-and-reverse motility, found in bacteria

480 having polar flagella, such as Vibrio species. In addition, some peritrichous bacteria

481 show swarming motility on a surface of semi-solid agar (Jarrel and McBride, 2008). B.

482 insecticola, that has one to three polar flagella (Fig. 1B), shows normal run-and-

483 tumbling motility in a liquid environment. However, in a viscous condition, a unique,

484 novel type of flagellar motility has been found in the Burkholderia symbiont, called

485 "corkscrew flagellar motility". In this particular swimming mode, the symbiont wraps

486 the flagellar filaments around the cell body and moves like a drill in the viscous

487 environment (Fig. 2F and G) (Kinoshita et al., 2018). Considering that this type of novel

488 motility has been reported in a few polar-flagellated bacteria including Vibrio fischeri

489 and Shewanella putrefaciens (Kinoshita et al., 2018; Kuhn et al, 2017), it is tempting to

490 speculate that the corkscrew motility contributes to the specific penetration of the

491 mucus-filled constricted region in the Burkholderia symbiont. To prove this hypothesis,

492 it will thus be of interest to analyze the corkscrew flagellar motility in other 
Burkholderia or Pandorea strains that can move into the M4 crypts or to identify the

494 genetic determinants of corkscrew motility in B. insecticola.

Midgut closure stimulated by symbiont colonization

497 In addition to the partner choice achieved by the selective passage through the

498 constricted region, a second layer mechanism for maintaining the Riptortus-

499 Burkholderia specificity was recently discovered. This mechanism also involves the

500 constricted region and is called the "midgut closure" (Kikuchi et al. submitted). In a few

501 hours after the Burkholderia symbiont starts penetrating into the constricted region and

502 colonizing the M4 crypts, the constricted region and the M4B, which are at first

503 permeable for the bacteria, become closed, completely preventing the entrance of

504 additional bacteria. Later on, after the full occupation of the M4 crypts with the

505 symbionts, the M4B region is re-opened and surplus symbiont cells from the crypts

506 flow back to the M4B, filling it with symbiont cells. Notably, even if the re-opening of

507 M4B occurs, the constricted region is kept firmly closed. This midgut closure prevents

508 additional colonization of the symbiotic region by symbiotic bacteria or any possible

509 contaminants and it thus contributes to preserve the specific colonization of the crypts.

511 Competition-based selection in the gut

512 As mentioned above, the capacity to pass through the constricted region and the

513 infection of the M4 crypts is not limited to the natural symbiont group of SBE

514 Burkholderia (Itoh et al., 2019). For example, Pandoraea norimbergensis and 
515 Burkholderia fungorum are capable to colonize the midgut crypts of $R$. pedestris (Fig.

516 3A-D), even though these common soil bacteria are usually not associated with the bean

517 bug in natural conditions. An additional partner choice mechanism, called "competition-

518 based selection", was put forward to explain this observed symbiont specificity (Itoh et

519 al., 2019). It was shown that the SBE Burkholderia always outcompete PBE

520 Burkholderia or Pandoraea species in the M4 region when these species are co-

521 infecting the symbiotic organ, achieving the predominance of SBE Burkholderia in the

522 bean bug gut (Fig. 3E-G). These experimental data clearly demonstrate that the abilities

523 for colonization and cooperation, usually thought of as specific traits of mutualists, are

524 not unique to the Burkholderia symbiont (i.e. SBE Burkholderia). On the contrary,

525 competitiveness inside the gut is a derived trait of the bean bug symbiont lineage only

526 (Fig. $3 \mathrm{H}$ ) and has thus played a critical role in the evolution of the insect gut symbiont.

527 Although at present the molecular bases of the in vivo competitiveness of the

528 Burkholderia symbiont remains unclear, the following four types of mechanisms can be 529 considered.

(i) Nutrient-based mechanism. Auxotrophic mutants of the Burkholderia

531 symbiont, such as purine biosynthes is mutants, show a severe crypt colonization defect

532 (Kim et al., 2014), suggesting that the M4 environment is nutritionally poor or there is a

533 selective repertoire of available nutrients. In fact, transcriptomic analyses revealed that

534 the Burkholderia symbiont actively proliferates by assimilating host' metabolic wastes,

535 such as sulfate and allanto in/urea, in M4 (Ohbayashi et al., 2019a). Adaptive abilities to 
536 the M4 nutritional environment probably affect the competitiveness and the selective

537 colonization of the Burkholderia symbiont. that the AMP resistance of $B$. insecticola plays an important role in stable colonization

540 of the symbiont in M4. For example, a deletion mutant of uppP (undecaprenyl

541 pyrophosphate phosphatase; involved in cell wall biosynthesis) becomes susceptible to

542 lysozymes in vitro and also shows a severe colonization defect in the M4 crypts (Kim et 543 al., 2013). Similarly, lipopolysaccharide (LPS) biosynthesis mutants, such as $\Delta w a b O$,

$544 \Delta w a a C$ and $\Delta w a a F$, also show decreased colonization ability in M4 (Kim et al., 2016;

545 Kim et al., 2017). It should be noted that transcriptomic analyses of M4 revealed that a

546 novel type of antimicrobial peptides (AMPs), called crypt-specific cysteine-rich

547 peptides (CCRs), are highly and specifically expressed in the midgut crypts (Futahashi

548 et al., 2013). Although the principal role of these crypt-specific AMPs remains unclear,

549 they may play a role in the symbiont's competitiveness and the in vivo selection 550 process.

(iii) Adhesion-based mechanism. Theoretical studies have predicted that

552 bacterial adhesion to gut epithelial cells has a selective advantage for competitive

553 colonization in the gut (McLoughlin et al., 2016). Genomic data indicates that the

554 Burkholderia symbiont possesses some Tad pilli and type I fimbriae, which may

555 contribute to the efficient colonization and competitiveness of the Burkholderia

556 symbiont. 
558 one of the well-known bacterial systems to directly inject anti-bacterial effectors and 559 inhibit competitors (Russell et al, 2014). The importance of T6SS in internal bacterial 560 competition has been reported in the squid-Vibrio symbiosis (Speare et al., 2018) and

561 the honey bee gut symbiosis (Steele et al., 2017). Although SBE Burkholderia have a 562 single type of T6SS, co-inoculation tests of PBE Burkholderia or Pandoraea and T6SS 563 deletion mutants of $B$. insecticola demonstrated that T6SS is not involved in the M4 564 competitiveness of the symbiont (Itoh et al., 2019). Some BCC\&P Burkholderia dispose 565 of another type of microbe-microbe toxin-delivery system, called "contact-dependent 566 growth inhibition (CDI)" (Garcia et al., 2016). However, the SBE Burkholderia do not

567 have any CDI genes. Hence, at this stage these direct systems do not seem to be 568 involved in the symbiont's in vivo competitiveness.

\section{Conclusion}

571 Although theoretical studies have proposed mechanisms for host-microbe mutualisms,

572 such as partner fidelity feedback, partner choice and sanction, competition-based 573 selection, and public goods theory (Archetti et al., 2011), it is not entirely clear how

574 mutualistic associations have evolved and are maintained. Furthermore, the genetic and 575 molecular bases of interspecific mutualisms are almost totally unclear in most of the 576 symbiotic systems, except a few model systems such as the legume-Rhizobium and 577 squid-Vibrio symbioses. The recent works on the Riportus-Burkholderia symbios is have 578 greatly improved our knowledge concerning the molecular bases of insect-microbe 
symbiosis with horizontal symbiont transmission. This useful model system contributes

580 to clarify how host-symbiont specificity evolved and is maintained in insect gut

581 symbiosis. In contrast, the genetic and molecular bases of the vertical symbiont

582 transmission remain unknown, despite the omnipresence of this type transmission in

583 insects. At this stage, only a few studies have tackled the question because reverse-

584 genetic approaches like RNAi and genome-editing do not efficiently work in many

585 insect models of endosymbiosis. Stinkbugs and beetles may be promising models

586 because they possess well-developed symbiotic systems and RNAi experiments are

587 possible in most cases. In fact, by use of the RNAi technique, recent studies have

588 succeeded in identifying a transcription factor and immune-related genes that play

589 pivotal roles in the maintenance of intracellular symbioses (Login et al., 2011; Maire et

590 al., 2019; Matsuura et al., 2015).

591 In insects, as summarized in this section, there are diverse vertical

592 transmission mechanisms involving highly sophisticated morphological features and

593 behaviors, as well as environmental acquisition mechanisms with well-developed

594 partner choice and competition-based mechanisms. It remains totally unknown how

595 such complex adaptive traits could evolve. The amazing diversity of microbial

596 symbioses in insects, in conjunction with the established molecular tools and the rapidly

597 progressed omics techniques, provides us a great opportunity to tackle this fundamental

598 but still enigmatic question.

599 
600 Acknowledgements

601 We thank Yoshiaki Kinoshita for kindly providing a microscopic image of the wrapping

602 motility. This study was supported by the JSPS-CNRS Bilateral Open Partnership Joint

603 Research Project to YK and PM, and the JSPS Research Fellowship for Young

604 Scientists to TO (19J01106).

605

606 Conflict of Interest

607 The authors declare that they have no competing interests.

608

609 


\section{References}

611 Anbutsu, H., Moriyama, M., Nikoh, N., Hosokawa, T., Futahashi, R., Tanahashi, M., Meng, X. Y., Kuriwada, T., Mori, N., Oshima, K., Hattori, M., Fujie, M., Satoh, N., Maeda, T., Shigenobu, S., Koga, R. and Fukatsu, T., 2017. Small genome symbiont underlies cuticle hardness in beetles. Proc. Natl. Acad. Sci. U. S. A. 114, E8382-E8391.

Archetti, M., Scheuring, I., Hoffman, M., Frederickson, M. E., Pierce, N. E. and Yu, D. W., 2011. Economic game theory for mutualism and cooperation. Ecol. Lett. 14, 1300-1312.

Aschtgen, M. S., Lynch, J. B., Koch, E., Schwartzman, J., McFall-Ngai, M. and Ruby, E., 2016a. Rotation of Vibrio fischeri flagella produces outer membrane vesicles that induce host development. J. Bacteriol. 198, 2156-2165.

Aschtgen, M. S., Wetzel, K., Goldman, W., McFall-Ngai, M. and Ruby, E., 2016b. Vibrio fischeri-derived outer membrane vesicles trigger host development. Cell. Microbiol. 18, 488-499.

Attardo, G. M., Lohs, C., Heddi, A., Alam, U. H., Yildirim, S. and Aksoy, S., 2008. Analysis of milk gland structure and function in Glossina morsitans: Milk protein

Bahram, M., Hildebrand, F., Forslund, S. K., Anderson, J. L., Soudzilovskaia, N. A., production, symbiont populations and fecundity. J. Insect. Physiol. 54, 1236Bodegom, P. M., Bengtsson-Palme, J., Anslan, S., Coelho, L. P., Harend, H., Huerta-Cepas, J., Medema, M. H., Maltz, M. R., Mundra, S., Olsson, P. A., Pent, 
M., Polme, S., Sunagawa, S., Ryberg, M., Tedersoo, L. and Bork, P., 2018. Structure and function of the global topsoil microbiome. Nature 560, 233-237.

Bansal, R., Michel, A. P. and Sabree, Z. L., 2014. The crypt-dwelling primary bacterial symbiont of the polyphagous pentatomid pest Halyomorpha halys (hemiptera: Pentatomidae). Environ. Entomol. 43, 617-625.

Beard, C. B., Cordon-Rosales C. and Durvasula, R. V., 2002. Bacterial symbionts of the Triatominae and their potential use in control of Chagas disease transmission. Annu. Rev. Entomol. 47, 123-141.

Beukes, C. W., Palmer, M., Manyaka, P., Chan, W. Y., Avontuur, J. R., van Zyl, E., Huntemann, M., Clum, A., Pillay, M., Palaniappan, K., Varghese, N., Mikhailova, N., Stamatis, D., Reddy, T. B. K., Daum, C., Shapiro, N., Markowitz, V., Ivanova, N., Kyrpides, N., Woyke, T., Blom, J., Whitman, W. B., Venter, S. N. and Steenkamp, E. T., 2017. Genome data provides high support for generic boundaries in Burkholderia sensu lato. Front. Microbiol. 8, 1154.

Bistolas, K. S., Sakamoto, R. I., Fernandes, J. A. and Goffredi, S. K., 2014. Symbiont polyphyly, co-evolution, and necessity in pentatomid stinkbugs from costa rica. Front. Microbiol. 5, 349 .

Boucias, D. G., Garcia-Maruniak, A., Cherry, R., Lu, H., Maruniak, J. E. and Lietze, V. U., 2012. Detection and characterization of bacterial symbionts in the heteropteran, Blissus insularis. FEMS Microbiol. Ecol. 82, 629-641. 
652

653

654

655

656

657

658

659

660

661

662

663

664

665

666

667

668

669

670

671

Bracke, J. W., Cruden, D. L. and Markovetz, A. J., 1978. Effect of metronidazole on the intestinal microflora of the american cockroach, Periplaneta americana $L$. Antimicrob. Agents Chemother. 13, 115-120.

Bright, M. and Bulgheresi, S., 2010. A complex journey: Transmission of microbial symbionts. Nat. Rev. Microbiol. 8, 218-230.

Brune, A. and Dietrich, C., 2015. The gut microbiota of termites: Digesting the diversity in the light of ecology and evolution. Annu. Rev. Microbiol. 69, 145166.

Buchner, P., 1965. Endosymbiosis of animals with plant microorganims. Interscience, New York.

Chun, C. K., Troll, J. V., Koroleva, I., Brown, B., Manzella, L., Snir, E., Almabrazi, H., Scheetz, T. E., de Fatima Bonaldo, M., Casavant, T. L., Soares, M. B., Ruby, E. G. and McFall-Ngai, M. J., 2008. Effects of colonization, luminescence, and autoinducer on host transcription during development of the squid-vibrio association. Proc. Natl. Acad. Sci. U. S. A. 105, 11323-11328.

D'Haeze, W. and Holsters, M., 2002. Nod factor structures, responses, and perception during initiation of nodule development. Glycobiology 12, 79R-105R.

Dasch, G., E. and Weiss, C.K., 1984. Endosymbionts of insects. In Krieg, N. A. (ed.), Bergey's Manual of Systematic Bacteriology, Vol. I, Williams and Wilkins, Baltimore, pp. 881-883. 
672 Davidson, S. K., Koropatnick, T. A., Kossmehl, R., Sycuro, L. and McFall- Ngai, M. J.,

673 2004. No means 'yes' in the squid-vibrio symbiosis: Nitric oxide (NO) during

674 the initial stages of a beneficial association. Cell. Microbiol. 6, 1139-1151.

675 Delgado-Baquerizo, M., Oliverio, A. M., Brewer, T. E., Benavent-González, A.,

676 Eldridge, D. J., Bardgett, R. D., Maestre, F. T., Singh, B. K. and Fierer, N., 2018.

677 A global atlas of the dominant bacteria found in soil. Science 359, 320-325.

678

679 Douglas, A. E., Minto, L. B. and Wilkinson, T. L., 2001. Quantifying nutrient

680 production by the microbial symbionts in an aphid. J. Exp. Biol. 204, 349-358.

681 Eberl, L. and Vandamme, P., 2016. Members of the genus Burkholderia: Good and bad

682 guys. F1000Res. 5, 1007.

683 Engel, P. and Moran, N. A., 2013. The gut microbiota of insects-diversity in structure 684 and function. FEMS Microbial. Rev. 37, 699-735.

685 Fukatsu, T. and Hosokawa, T., 2002. Capsule-transmitted gut symbiotic bacterium of 686 the japanese common plataspid stinkbug, Megacopta punctatissima. Appl.

687 Environ. Microbiol. 68, 389-396.

688 Futahashi, R., Tanaka, K., Matsuura, Y., Tanahashi, M., Kikuchi, Y. and Fukatsu, T., 689 2011. Laccase2 is required for cuticular pigmentation in stinkbugs. Insect 690 Biochem. Mol. Biol. 41, 191-196. 
691 Futahashi, R., Tanaka, K., Tanahashi, M., Nikoh, N., Kikuchi, Y., Lee, B. L. and

692 Fukatsu, T., 2013. Gene expression in gut symbiotic organ of stinkbug affected by 693 extracellular bacterial symbiont. PLoS One 8, e64557.

694 Garcia, E. C., Perault, A. I., Marlatt, S. A. and Cotter, P. A., 2016. Interbacterial 695 signaling via Burkholderia contact-dependent growth inhibition system proteins.

696 Proc. Natl. Acad. Sci. U. S. A. 113, 8296-8301.

697 Garcia, J. R., Laughton, A. M., Malik, Z., Parker, B. J., Trincot, C., S, S. L. C., Chung, 698 E. and Gerardo, N. M., 2014. Partner associations across sympatric broad-headed 699 bug species and their environmentally acquired bacterial symbionts. Mol. Ecol.

700 $23,1333-1347$.

701 Goettler, W., Kaltenpoth, M., Herzner, G. and Strohm, E., 2007. Morphology and 702

Gordon, E. R., McFrederick, Q. and Weirauch, C., 2016. Phylogenetic evidence for ancient and persistent environmental symbiont reacquisition in Largidae (Hemiptera: Heteroptera). Appl. Environ. Microbiol. 82, 7123-7133.

708 Graf, J., Dunlap, P. V. and Ruby, E. G., 1994. Effect of transposon-induced motility 709 mutations on colonization of the host light organ by Vibrio fischeri. J. Bacteriol. 176, 6986-6991. 
711 Hayashi, T., Hosokawa, T., Meng, X. Y., Koga, R. and Fukatsu, T., 2015. Femalespecific specialization of a posterior end region of the midgut symbiotic organ in Plautia splendens and allied stinkbugs. Appl. Environ. Microbiol. 81, 2603-2611.

714 Hosokawa, T., Hironaka, M., Inadomi, K., Mukai, H., Nikoh, N. and Fukatsu, T., 2013. Diverse strategies for vertical symbiont transmission among subsocial stinkbugs. PLoS One 8, e65081.

Hosokawa, T., Kikuchi, Y. and Fukatsu, T., 2007. How many symbionts are provided by mothers, acquired by offspring, and needed for successful vertical transmission in an obligate insect-bacterium mutualism? Mol. Ecol. 16, 5316-5325.

Hosokawa, T., Kikuchi, Y., Meng, X. Y. and Fukatsu, T., 2005. The making of symbiont capsule in the plataspid stinkbug Megacopta punctatissima. FEMS Microbial. Ecol. 54, 471-477.

Hosokawa, T., Kikuchi, Y., Nikoh, N., Shimada, M. and Fukatsu, T., 2006. Strict hostsymbiont cospeciation and reductive genome evolution in insect gut bacteria.

Hosokawa, T., Kikuchi, Y., Shimada, M. and Fukatsu, T., 2008. Symbiont acquisition PLoS Biol. 4, e337.

Hosokawa, T., Koga, R., Kikuchi, Y., Meng, X. Y. and Fukatsu, T., 2010. Wolbachia as a bacteriocyte-associated nutritional mutualist. Proc. Natl. Acad. Sci. U. S. A. alters behaviour of stinkbug nymphs. Biol. Lett. 4, 45-48.

Hosokawa, T., Matsuura, Y., Kikuchi, Y. and Fukatsu, T., 2016. Recurrent evolution of gut symbiotic bacteria in pentatomid stinkbugs. Zoological Lett. 2, 24. 
Hosokawa, T., Nikoh, N., Koga, R., Sato, M., Tanahashi, M., Meng, X. Y. and Fukatsu, T., 2012. Reductive genome evolution, host-symbiont co-speciation and uterine transmission of endosymbiotic bacteria in bat flies. ISME J. 6, 577-587.

Itoh, H., Aita, M., Nagayama, A., Meng, X. Y., Kamagata, Y., Navarro, R., Hori, T., Ohgiya, S. and Kikuchi, Y., 2014. Evidence of environmental and vertical transmission of Burkholderia symbionts in the oriental chinch bug, Cavelerius saccharivorus (Heteroptera: Blissidae). Appl. Environ. Microbiol. 80, 5974-5083.

Itoh, H., Hori, T., Sato, Y., Nagayama, A., Tago, K., Hayatsu, M. and Kikuchi, Y., 2018a. Infection dynamics of insecticide-degrading symbionts from soil to insects in response to insecticide spraying. ISME J. 12, 909-920.

Itoh, H., Jang, S., Takeshita, K., Ohbayashi, T., Ohnishi, N., Meng, X. Y., Mitani, Y. and Kikuchi, Y., 2019. Host-symbiont specificity determined by microbe-microbe competition in an insect gut. Proc. Natl. Acad. Sci. U. S. A. 116, 22673-22682.

Itoh, H., Matsuura, Y., Hosokawa, T., Fukatsu, T. and Kikuchi, Y., 2016. Obligate gut symbiotic association in the sloe bug Dolycoris baccarum (Hemiptera: Pentatomidae). Appl. Entomol. Zool. 52, 51-59.

Itoh, H., Tago, K., Hayatsu, M. and Kikuchi, Y., 2018b. Detoxifying symbiosis: Microbe-mediated detoxification of phytotoxins and pesticides in insects. Nat. Prod. Rep. 35, 434-454.

Jarrell, K. F. and McBride, M. J., 2008. The surprisingly diverse ways that prokaryotes move. Nat. Rev. Microbiol. 6, 466-476. 
754 Jung, M. and Lee, D. H., 2019. Abundance and diversity of gut-symbiotic bacteria, the 755 genus Burkholderia in overwintering Riptortus pedestris (Hemiptera: Alydidae) populations and soil in South Korea. PLoS One 14, e0218240.

757

Kaiwa, N., Hosokawa, T., Nikoh, N., Tanahashi, M., Moriyama, M., Meng, X. Y., Maeda, T., Yamaguchi, K., Shigenobu, S., Ito, M. and Fukatsu, T., 2014. Symbiont-supplemented maternal investment underpinning host's ecological adaptation. Curr. Biol. 24, 2465-2470.

Kaltenpoth, M. and Flórez, L. V., 2019. Versatile and dynamic symbioses between insects and burkholderia bacteria. Annu. Rev. Entomol. doi: 10.1146/annurevento-011019-025025. [Epub ahead of print].

Kaltenpoth, M., Gottler, W., Herzner, G. and Strohm, E., 2005. Symbiotic bacteria protect wasp larvae from fungal infestation. Curr. Biol. 15, 475-479.

Kaltenpoth, M., Roeser-Mueller, K., Koehler, S., Peterson, A., Nechitaylo, T. Y., Stubblefield, J. W., Herzner, G., Seger, J. and Strohm, E., 2014. Partner choice and fidelity stabilize coevolution in a cretaceous-age defensive symbiosis. Proc. Natl. Acad. Sci. U. S. A. 111, 6359-6364.

Kaltenpoth, M., Schmitt, T., Polidori, C., Koedam, D. and Strohm, E., 2010. Symbiotic streptomycetes in antennal glands of the south american digger wasp genus Trachypus (Hymenoptera, Crabronidae). Physiol. Entomol. 35, 196-200.

Karamipour, N., Fathipour, Y. and Mehrabadi, M., 2016. Gammaproteobacteria as essential primary symbionts in the striped shield bug, Graphosoma lineatum (Hemiptera: Pentatomidae). Sci. Rep. 6, 33168. 
Kashkouli, M., Fathipour, Y. and Mehrabadi, M., 2019. Habitat visualization, acquisition features and necessity of the gammaproteobacterial symbiont of pistachio stink bug, Acrosternum heegeri (Hem.: Pentatomidae). Bull. Entomol. Res. 1-12.

Kashkouli, M., Fathipour, Y. and Mehrabadi, M., 2019. Heritable gammaproteobacterial symbiont improves the fitness of Brachynema germari Kolenati (Hemiptera: Pentatomidae). Environ. Entomol. 48, 1079-1087.

Kashkouli, M., Fathipour, Y. and Mehrabadi, M., 2019. Potential management tactics for pistachio stink bugs, Brachynema germari, Acrosternum heegeri and Acrosternum arabicum (hemiptera: Pentatomidae): High temperature and chemical surface sterilants leading to symbiont suppression. J. Econ. Entomol. $112,244-254$.

Kenyon, L. J., Meulia, T. and Sabree, Z. L., 2015. Habitat visualization and genomic analysis of "Candidatus Pantoea carbekii," the primary symbiont of the brown marmorated stink bug. Genome Biol. Evol. 7, 620-635.

Kiers, E. T., Rousseau, R. A., West, S. A. and Denison, R. F., 2003. Host sanctions and the legume-rhizobium mutualism. Nature 425, 78.

Kikuchi, Y., 2009. Endosymbiotic bacteria in insects: Their diversity and culturability. Microbes and environments Microbe. Environ. 24, 195-204.

Kikuchi, Y. and Fukatsu, T., 2014. Live imaging of symbiosis: Spatiotemporal infection dynamics of a GFP-labelled Burkholderia symbiont in the bean bug Riptortus pedestris. Mol. Ecol. 23, 1445-1456. 
Kikuchi, Y., Hosokawa, T. and Fukatsu, T., 2007. Insect-microbe mutualism without vertical transmission: A stinkbug acquires a beneficial gut symbiont from the environment every generation. Appl. Environ. Microbiol. 73, 4308-4316.

Kikuchi, Y., Hosokawa, T. and Fukatsu, T., 2011a. An ancient but promiscuous hostsymbiont association between Burkholderia gut symbionts and their heteropteran hosts. ISME J. 5, 446-460.

Kikuchi, Y., Hosokawa, T. and Fukatsu, T., 2011b. Specific developmental window for establishment of an insect-microbe gut symbiosis. Appl. Environ. Microbiol. 77, 4075-4081.

Kikuchi, Y., Hosokawa, T., Nikoh, N. and Fukatsu, T., 2012. Gut symbiotic bacteria in the cabbage bugs Eurydema rugosa and Eurydema dominulus (Heteroptera: Pentatomidae). Appl. Entomol. Zool. 47, 1-8.

Kikuchi, Y., Hosokawa, T., Nikoh, N., Meng, X. Y., Kamagata, Y. and Fukatsu, T., 2009. Host-symbiont co-speciation and reductive genome evolution in gut symbiotic bacteria of acanthosomatid stinkbugs. BMC Biol. 7, 2.

Kikuchi, Y., Meng, X. Y. and Fukatsu, T., 2005. Gut symbiotic bacteria of the genus Burkholderia in the broad-headed bugs Riptortus clavatus and Leptocorisa chinensis (Heteroptera: Alydidae). Appl. Environ. Microbiol. 71, 4035-4043.

Kikuhara, Y., 2005. The Japanese species of the genus Riptortus (Heteroptera, Alydidae) with description of a new species. Jpn. J. Syst. Entomol. 11, 299-311.

Kim, J. K., Jang, H. A., Kim, M. S., Cho, J. H., Lee, J. B., Lorenzo, F. D., Sturiale, L., Silipo, A., Molinaro, A. and Lee, B. L., 2017. The lipopolysaccharide core 
oligosaccharide of Burkholderia plays a critical role in maintaining a proper gut symbiosis with the bean bug Riptortus pedestris. J. Biol. Chem. 292, 1922619237.

Kim, J. K., Jang, H. A., Won, Y. J., Kikuchi, Y., Heum Han, S., Kim, C. H., Nikoh, N.,

Kim, J. K., Lee, H. J., Kikuchi, Y., Kitagawa, W., Nikoh, N., Fukatsu, T. and Lee, B. Fukatsu, T. and Lee, B. L., 2014. Purine biosynthesis-deficient Burkholderia mutants are incapable of symbiotic accommodation in the stinkbug. ISME J. 8, Immunol. 60, 202-208.

Kinosita, Y., Kikuchi, Y., Mikami, N., Nakane, D. and Nishizaka, T., 2018. Unforeseen swimming and gliding mode of an insect gut symbiont, Burkholderia sp. Rpe64,

839 Koga, R., Meng, X. Y., Tsuchida, T. and Fukatsu, T., 2012. Cellular mechanism for with wrapping of the flagella around its cell body. ISME J. 12, 838-848.

Koch, H. and Schmid-Hempel, P., 2011. Socially transmitted gut microbiota protect bumble bees against an intestinal parasite. Proc. Natl. Acad. Sci. U. S. A. 108, selective vertical transmission of an obligate insect symbiont at the bacteriocyteembryo interface. Proc. Natl. Acad. Sci. U. S. A. 109, E1230-E1237. 
842 Koropatnick, T. A., Engle, J. T., Apicella, M. A., Stabb, E. V., Goldman, W. E. and

843 McFall-Ngai, M. J., 2004. Microbial factor-mediated development in a host-

844 bacterial mutualism. Science 306, 1186-1188.

845 Krasity, Benjamin C., Troll, Joshua V., Weiss, Jerrold P. and McFall-Ngai, Margaret J.,

846 2011. LBP/BPI proteins and their relatives: Conservation over evolution and roles

847 in mutualism. Biochem. Soc. Trans. 39, 1039-1044.

848

849 Kroiss, J., Kaltenpoth, M., Schneider, B., Schwinger, M. G., Hertweck, C., Maddula, R.

850 K., Strohm, E. and Svatos, A., 2010. Symbiotic streptomycetes provide antibiotic

851 combination prophylaxis for wasp offspring. Nat. Chem. Biol. 6, 261-263.

852 Kuechler, S. M., Matsuura, Y., Dettner, K. and Kikuchi, Y., 2016. Phylogenetically

853 diverse Burkholderia associated with midgut crypts of spurge bugs,

854 Dicranocephalus spp. (Heteroptera: Stenocephalidae). Microbes Environ. 31,

$855 \quad 145-153$.

856 Kuhn, M. J., Schmidt, F. K., Eckhardt, B. and Thormann, K. M., 2017. Bacteria exploit

857 a polymorphic instability of the flagellar filament to escape from traps. Proc. Natl.

$858 \quad$ Acad. Sci. U. S. A. 114, 6340-6345.

859 Login, F. H., Balmand, S., Vallier, A., Vincent-Monegat, C., Vigneron, A., Weiss-

860 Gayet, M., Rochat, D. and Heddi, A., 2011. Antimicrobial peptides keep insect

861 endosymbionts under control. Science 334, 362-365.

862 Mahenthiralingam, E., Urban, T. A. and Goldberg, J. B., 2005. The multifarious,

863 multireplicon Burkholderia cepacia complex. Nat. Rev Microbiol. 3, 144-156. 
864 Maire, J., Vincent-Monegat, C., Balmand, S., Vallier, A., Herve, M., Masson, F.,

865 Parisot, N., Vigneron, A., Anselme, C., Perrin, J., Orlans, J., Rahioui, I., Da Silva,

866 P., Fauvarque, M. O., Mengin-Lecreulx, D., Zaidman-Remy, A. and Heddi, A., 867 2019. Weevil pgrp-lb prevents endosymbiont TCT dissemination and chronic host 868 systemic immune activation. Proc. Natl. Acad. Sci. U. S. A. 116, 5623-5632.

869 Matsuura, Y., Kikuchi, Y., Miura, T. and Fukatsu, T., 2015. Ultrabithorax is essential 870 for bacteriocyte development. Proc. Natl. Acad. Sci. U. S. A. 112, 9376-9381.

871 McCutcheon, J.P. and Moran, N. A., 2012. Extreme genome reduction in symbiotic 872 bacteria. Nat. Rev. Microbiol. 10, 13-26.

873 McLoughlin, K., Schluter, J., Rakoff-Nahoum, S., Smith, A. L. and Foster, K. R., 2016. 874 Host selection of microbiota via differential adhesion. Cell Host Microbe 19, 550875 559.

876 Mergaert, P., 2018. Role of antimicrobial peptides in controlling symbiotic bacterial populations. Nat. Prod. Rep. 35, 336-356.

878 Millikan, D. S. and Ruby, E. G., 2003. FlrA, a 54-dependent transcriptional activator in 879 Vibrio fischeri, is required for motility and symbiotic light-organ colonization. J. $880 \quad$ Bacteriol. 185, 3547-3557.

881 Millikan, D. S. and Ruby, E. G., 2004. Vibrio fischeri flagellin a is essential for normal 882 motility and for symbiotic competence during initial squid light organ 883 colonization. J. Bacteriol. 186, 4315-4325.

884 Miyamoto, S., 1961. Comparative morphology of alimentary organs of Heteroptera, 885 with the phylogenetic consideration. Sieboldia 2, 197-259. 
Moran, N. A. and Bennett, G. M., 2014. The tiniest tiny genomes. Annu. Rev. Microbiol. 68, 195-215.

Moran, N. A., Russell, J. A., Koga, R. and Fukatsu, T., 2005. Evolutionary relationships of three new species of Enterobacteriaceae living as symbionts of aphids and other insects. Appl. Environ. Microbiol. 71, 3302-3310.

Moya, A., Pereto, J., Gil, R. and Latorre, A., 2008. Learning how to live together: Genomic insights into prokaryote-animal symbioses. Nat. Rev. Gen. 9, 218-229.

Nyholm, S. V. and Graf, J., 2012. Knowing your friends: Invertebrate innate immunity fosters beneficial bacterial symbioses. Nat. Rev. Microbiol. 10, 815-827.

Nyholm, S. V. and McFall-Ngai, M., 2004. The winnowing: Establishing the squidVibrio symbiosis. Nat. Rev. Microbiol. 2, 632-642.

Nyholm, S. V., Stabb, E. V., Ruby, E. G. and McFall-Ngai, M. J., 2000. Establishment of an animal-bacterial association: Recruiting symbiotic vibrios from the environment. Proc. Natl. Acad. Sci. U. S. A. 97, 10231-10235.

Ohbayashi, T., Futahashi, R., Terashima, M., Barriere, Q., Lamouche, F., Takeshita, K., 901 Meng, X. Y., Mitani, Y., Sone, T., Shigenobu, S., Fukatsu, T., Mergaert, P. and Kikuchi, Y., 2019a. Comparative cytology, physiology and transcriptomics of Burkholderia insecticola in symbiosis with the bean bug Riptortus pedestris and in culture. ISME J. 13, 1469-1483. gut symbionts associated with European and Japanese populations of the dock bug Coreus Marginatus (Coreoidea: Coreidae). Microbes Environ. 34, 219-222. 
908

909

910

911

912

913

914

915

916

917

918

919

920

921

922

923

924

925

926

927

928

929

Ohbayashi, T., Takeshita, K., Kitagawa, W., Nikoh, N., Koga, R., Meng, X. Y., Tago, K., Hori, T., Hayatsu, M., Asano, K., Kamagata, Y., Lee, B. L., Fukatsu, T. and Kikuchi, Y., 2015. Insect's intestinal organ for symbiont sorting. Proc. Natl. Acad. Sci. U. S. A. 112, E5179-E5188.

Ohkuma, M. and Brune, A., 2010. Diversity, structure, and evolution of the termite gut microbial community. Bignell DE, Roisin Y, \& Lo N (Eds.), Biology of Termites: A Modern Synthesis. Springer Netherlands, Dordrecht, pp 413-438.

Oliver, K. M., Degnan, P. H., Burke, G. R. and Moran, N. A., 2010. Facultative symbionts in aphids and the horizontal transfer of ecologically important traits. Annu. Rev. Entomol. 55, 247-266.

Olivier-Espejel, S., Sabree, Z. L., Noge, K. and Becerra, J. X., 2011. Gut microbiota in nymph and adults of the giant mesquite bug (Thasus neocalifornicus) (Heteroptera: Coreidae) is dominated by Burkholderia acquired de novo every generation. Environ. Entomol. 40, 1102-1110.

Onchuru, T. O., Javier Martinez, A., Ingham, C. S. and Kaltenpoth, M., 2018. Transmission of mutualistic bacteria in social and gregarious insects. Curr. Opin. Insect Sci. 28, 50-58.

Peeters, C., Meier-Kolthoff, J. P., Verheyde, B., De Brandt, E., Cooper, V. S. and Vandamme, P., 2016. Phylogenomic study of Burkholderia glathei-like organisms, proposal of 13 novel Burkholderia species and emended descriptions of Burkholderia sordidicola, Burkholderia zhejiangensis, and Burkholderia grimmiae. Front. Microbiol. 7, 877. 
Poole, P., Ramachandran, V. and Terpolilli, J., 2018. Rhizobia: From saprophytes to endosymbionts. Nat. Rev. Microbiol. 16, 291-303.

Powell, J. E., Martinson, V. G., Urban-Mead, K. and Moran, N. A., 2014. Routes of acquisition of the gut microbiota of the honey bee Apis mellifera. Appl. Environ. Microbiol. 80, 7378-7387.

Prado, S. S., Golden, M., Follett, P. A., Daugherty, M. P. and Almeida, R. P., 2009. Demography of gut symbiotic and aposymbiotic Nezara viridula L. (Hemiptera: Pentatomidae). Environ. Entomol. 38, 103-109.

Prado, S. S., Rubinoff, D. and Almeida, R. P. P., 2006. Vertical transmission of a pentatomid caeca-associated symbiont. Annu. Entomol. Soc. Am. 99, 577-585.

Russell, A. B., Peterson, S. B. and Mougous, J. D., 2014. Type VI secretion system effectors: Poisons with a purpose. Nat. Rev. Microbiol. 12, 137-148.

Sachs, J. L., Mueller, U. G., Wilcox, T. P. and Bull, J. J., 2004. The quarterly review of biology. Q. Rev. Biol. 79, 135-160.

Salem, H., Bauer, E., Kirsch, R., Berasategui, A., Cripps, M., Weiss, B., Koga, R., Fukumori, K., Vogel, H., Fukatsu, T. and Kaltenpoth, M., 2017. Drastic genome reduction in an herbivore's pectinolytic symbiont. Cell 171, 1520-1531 e1513.

Salem, H., Florez, L., Gerardo, N. and Kaltenpoth, M., 2015. An out-of-body experience: The extracellular dimension for the transmission of mutualistic bacteria in insects. Proc. Biol. Sci. 282, 20142957. 
Sangare, A. K., Rolain, J. M., Gaudart, J., Weber, P. and Raoult, D., 2016. Synergistic activity of antibiotics combined with ivermectin to kill body lice. Int. J. Antimicrob. Agents 47, 217-223.

953

Schaefer, C. W. and Panizzi, A. R., 2000. Heteroptera of economic importance. CRC press, Boca Raton.

Schlein, Y., 1977. Lethal effect of tetracycline on tsetse flies following damage to bacterioid symbionts. Experientia 33, 450-451.

957

Shibata, T. F., Maeda, T., Nikoh, N., Yamaguchi, K., Oshima, K., Hattori, M., Nishiyama, T., Hasebe, M., Fukatsu, T., Kikuchi, Y. and Shigenobu, S., 2013. Complete genome sequence of Burkholderia sp. strain RPE64, bacterial symbiont

961 Small, A. L. and McFall-Ngai, M. J., 1999. Halide peroxidase in tissues that interact 962 with bacteria in the host squid Euprymna scolopes. J. Cell. Biochem. 72, 445-457.

963 Speare, L., Cecere, A. G., Guckes, K. R., Smith, S., Wollenberg, M. S., Mandel, M. J., 964 Miyashiro, T. and Septer, A. N., 2018. Bacterial symbionts use a type VI secretion 965 system to eliminate competitors in their natural host. Proc. Natl. Acad. Sci. U. S. 966

967 Srivastava, P. and Auclair, J., 1976. Effects of antibiotics on feeding and development 968 of the pea aphid, Acyrthosiphon pisum (Harris) (Homoptera: Aphididae). Can. J. 969 Zool. 54, 1025-1029. 
970

971

972

973

974

975

976

977

978

979

980

981

982

983

984

985

986

987

988

989

990

991

Steele, M. I., Kwong, W. K., Whiteley, M. and Moran, N. A., 2017. Diversification of type VI secretion system toxins reveals ancient antagonism among bee gut microbes. mBio 8, e01630-01617.

Suárez-Moreno, Z. R., Caballero-Mellado, J., Coutinho, B. G., Mendonca-Previato, L., James, E. K. and Venturi, V., 2012. Common features of environmental and potentially beneficial plant-associated Burkholderia. Microb. Ecol. 63, 249-266.

Sudakaran, S., Kost, C. and Kaltenpoth, M., 2017. Symbiont acquisition and replacement as a source of ecological innovation. Trends Microbiol. 25, 375-390.

Sudakaran, S., Retz, F., Kikuchi, Y., Kost, C. and Kaltenpoth, M., 2015. Evolutionary transition in symbiotic syndromes enabled diversification of phytophagous insects on an imbalanced diet. ISME J. 9, 2587-2604.

Tada, A., Kikuchi, Y., Hosokawa, T., Musolin, D. L., Fujisaki, K. and Fukatsu, T., 2011. Obligate association with gut bacterial symbiont in Japanese populations of the southern green stinkbug Nezara viridula (Heteroptera: Pentatomidae). Appl. Entomol. Zool. 46, 483-488.

Takeshita, K. and Kikuchi, Y., 2017. Riptortus pedestris and Burkholderia symbiont: An ideal model system for insect-microbe symbiotic associations. Res. Microbiol. $168,175-187$.

Takeshita, K., Matsuura, Y., Itoh, H., Navarro, R., Hori, T., Sone, T., Kamagata, Y., Mergaert, P. and Kikuchi, Y., 2015. Burkholderia of plant-beneficial group are symbiotically associated with bordered plant bugs (Heteroptera: Pyrrhocoroidea: Largidae). Microbes Environ. 30, 321-329. 
992 Takeshita, K., Shibata, T. F., Nikoh, N., Nishiyama, T., Hasebe, M., Fukatsu, T., 993 Shigenobu, S. and Kikuchi, Y., 2014. Whole-genome sequence of Burkholderia 994 sp. strain RPE67, a bacterial gut symbiont of the bean bug Riptortus pedestris. 995 Genome Announc. 2, e00556-14.

996 Takeshita, K., Tamaki, H., Ohbayashi, T., Meng, X.-Y., Sone, T., Mitani, Y., Peeters, 997 C., Kikuchi, Y. and Vandamme, P., 2018. Burkholderia insecticola sp. nov., a gut 998 symbiotic bacterium of the bean bug Riptortus pedestris. Int. J. Syst. Evol. $999 \quad$ Microbiol. 68, 2370-2374.

1000 Taylor, C. M., Coffey, P. L., DeLay, B. D. and Dively, G. P., 2014. The importance of 1001 1002 gut symbionts in the development of the brown marmorated stink bug, Halyomorpha halys (Stal). PLoS One 9, e90312.

1003 Troll, J. V., Adin, D. M., Wier, A. M., Paquette, N., Silverman, N., Goldman, W. E., 1004 Stadermann, F. J., Stabb, E. V. and McFall-Ngai, M. J., 2009. Peptidoglycan 1005 induces loss of a nuclear peptidoglycan recognition protein during host tissue 1006 development in a beneficial animal-bacterial symbiosis. Cell. Microbiol. 11, $1007 \quad 1114-1127$. neutralizes a bacterial symbiont toxin. Environ. Microbiol. 12, 2190-2203.

1011 Visick, K. L. and Ruby, E. G., 2006. Vibrio fischeri and its host: It takes two to tango. 1012 Curr. Opin. Microbiol. 9, 632-638. 
1013 Wang, Q., Liu, J. and Zhu, H., 2018. Genetic and molecular mechanisms underlying 1014 symbiotic specificity in legume-rhizobium interactions. Front. Plant Sci. 9, 313. 1015 Weis, V. M., Small, A. L. and McFall-Ngai, M. J., 1996. A peroxidase related to the 1016 mammalian antimicrobial protein myeloperoxidase in the Euprymna1017 Vibrio mutualism. Proc. Natl. Acad. Sci. U. S. A. 93, 13683-13688.

$1018 \mathrm{Xu}$, Y., Buss, E. A. and Boucias, D. G., 2016. Environmental transmission of the gut 1019 symbiont Burkholderia to phloem-feeding Blissus insularis. PLoS One 11, $1020 \quad \mathrm{e} 0161699$.

1021

1022

1023 
1025 Figure 1. Gut symbiosis between the bean bug Riptortus pedestris and its symbiont 1026 Burkholderia insecticola.

1027 (A) A female adult of the bean bug R. pedestris. (B) B. insecticola. (C) Whole midgut of $1028 R$. pedestris. (D-G) A GFP-labeled strain of $B$. insecticola colonizes the posterior region 1029 of the midgut (D-E), in which GFP signals are specifically detected in the crypt-bearing 1030 symbiotic region (E-G). Abbreviations: M1, midgut first section; M2, midgut second 1031 section; M3, midgut third section; M4, midgut fourth section with crypts; M4B, M4 1032 bulb; CR, constricted region; H, hindgut. Each crypt is indicated by arrowheads in F 1033 and G. Panels B and C are from Ohbayashi et al. 2015.

1034

1035 Figure 2. Partner-choice in the gut of $\boldsymbol{R}$. pedestris.

1036 (A) A midgut fed with water containing $0.05 \%$ food coloring (congo red). Note that the

1037 coloring is blocked at the constricted region. (B) A midgut infected with GFP-labeled $B$. 1038 insecticola showing that the bacteria can flow from M3 into M4B by passing through 1039 the constricted region. (C) Electron microscopy image of the narrow channel in the 1040 constricted region. The lumen of the channel is bordered by a layer of microvilli (ML)

1041 and contains a few bacterial cells (S) that are passing through the channel. (D) The 1042 constricted region in an insect co-inoculated with a GFP-labeled B. insecticola and an 1043 RFP-labeled E. coli. At the constricted region, E. coli is sorted out and only the

1044 Burkholderia symbiont passes through the channel. (E) Normal swimming mode of $B$. 1045 insecticola in a liquid environment. (F) Corkscrew motility of $B$. insecticola in a 
1046 viscous environment. Flagellar filaments are visualized by covalent coupling to the

1047 fluorescent dye Cy3-NHS-ester. Panels A, C and D are from Ohbayashi et al. 2015.

1048

1049 Figure 3. Microbe-microbe competition in the gut of $\boldsymbol{R}$. pedestris.

1050 Midgut M3-M4B-M4 regions of (A) an aposymbiotic insect; (B) an insect infected with

1051 a SBE Burkholderia (B. insecticola); (C) an insect infected with a PBE Burkholderia

1052 (B. fungorum); (D) an insect infected with Pandoraea (P. norimbergensis). (E-G) M4

1053 region of an insect inoculated with an RFP-labeled SBE Burkholderia (B. insecticola)

1054 and an RFP-labeled Pandoraea (P. norimbergensis) at 2, 3, and 5 days post inoculation

1055 (dpi). (H) The schematic image of a symbiont specificity in the midgut of the bean bug

1056 R. pedestris. In the early infection stage, SBE-Burkholderia, PBE Burkholderia, and

1057 Pandoraea co-colonize the M4 (left). In the mature stage, SBE Burkholderia

1058 outcompetes the other strains and becomes dominant in the M4 (right). Panels A-G are

1059 from Itoh et al. 2019.

1060 
Fig. 1

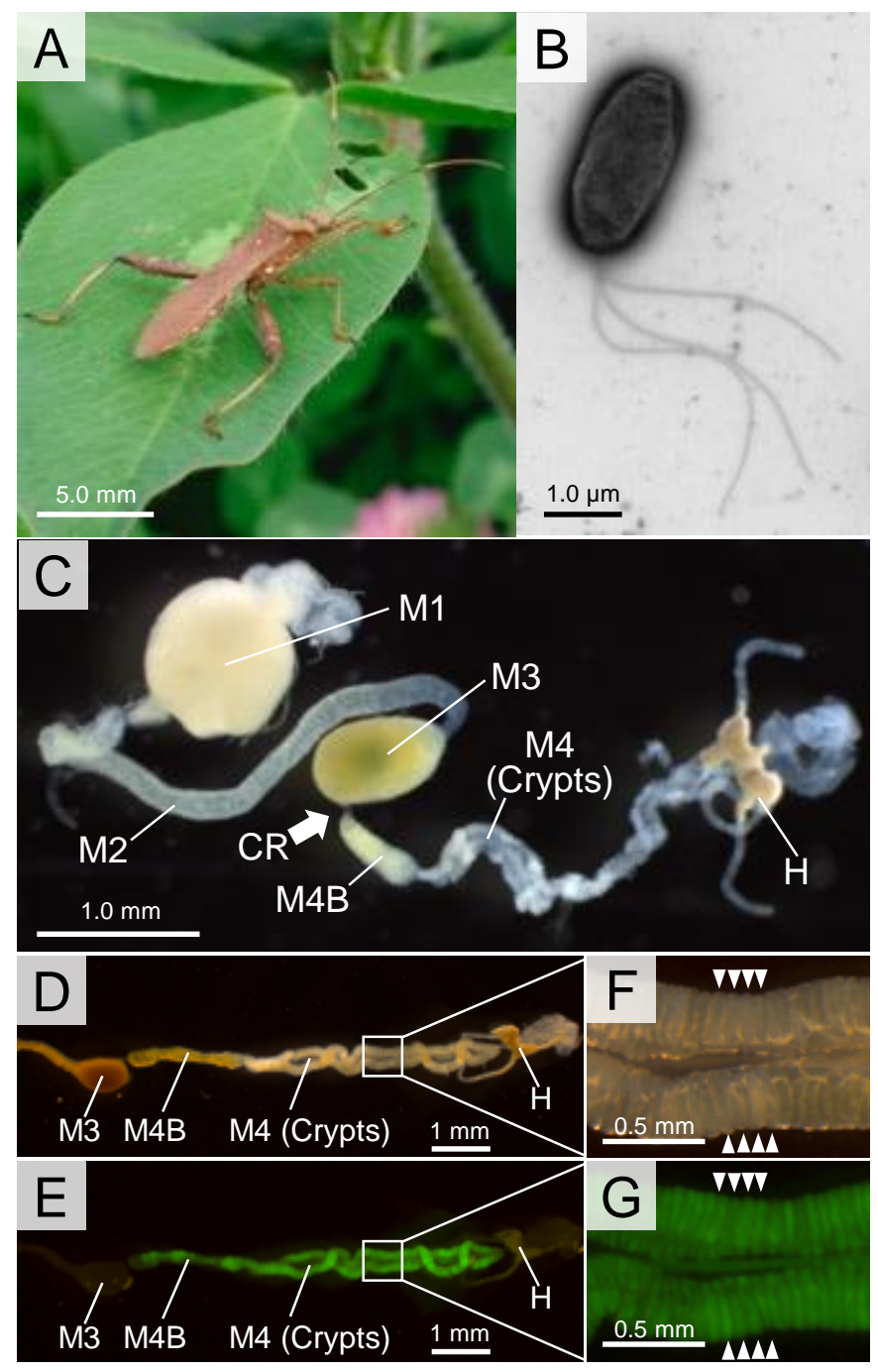


Fig. 2

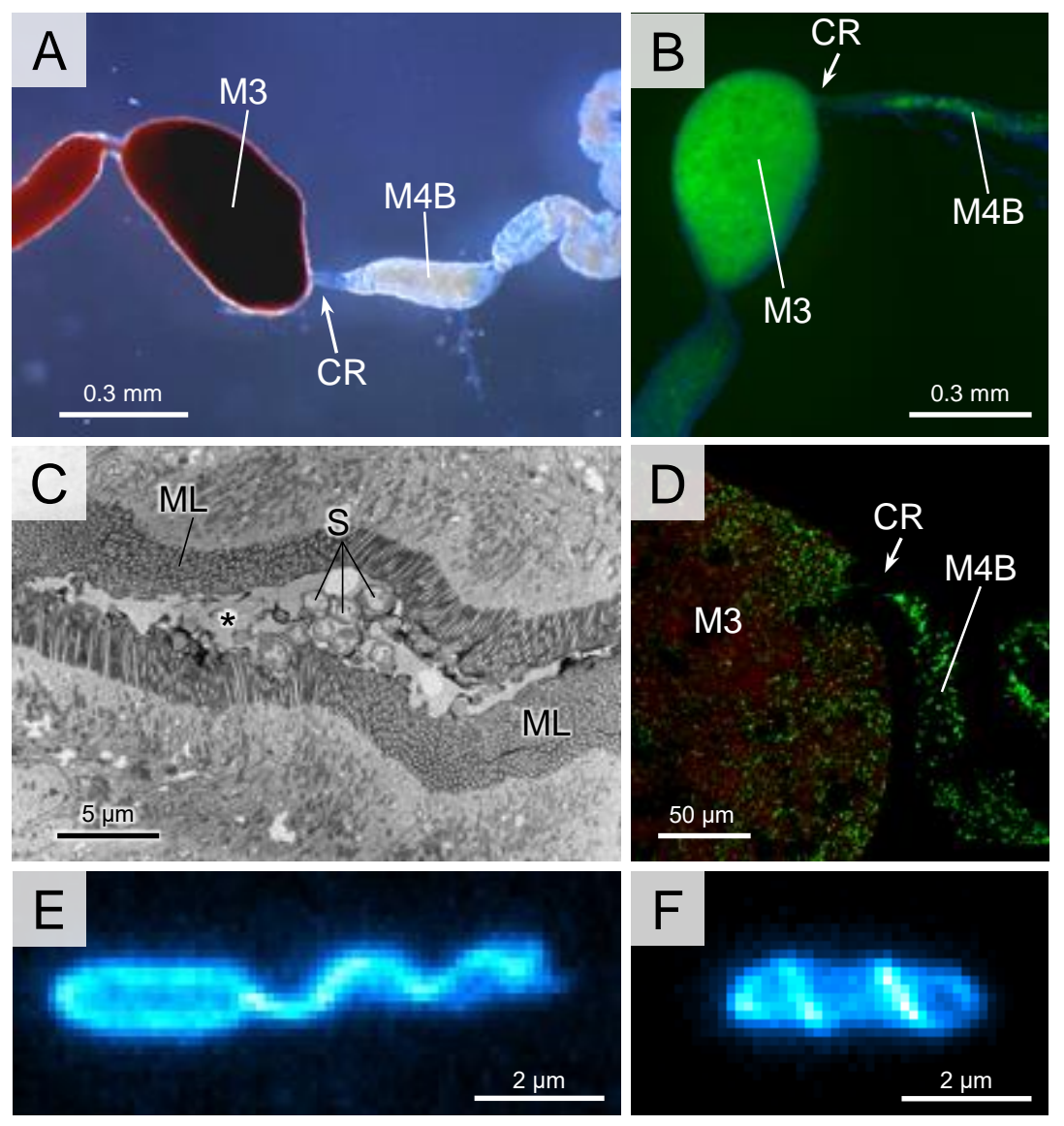


Fig. 3
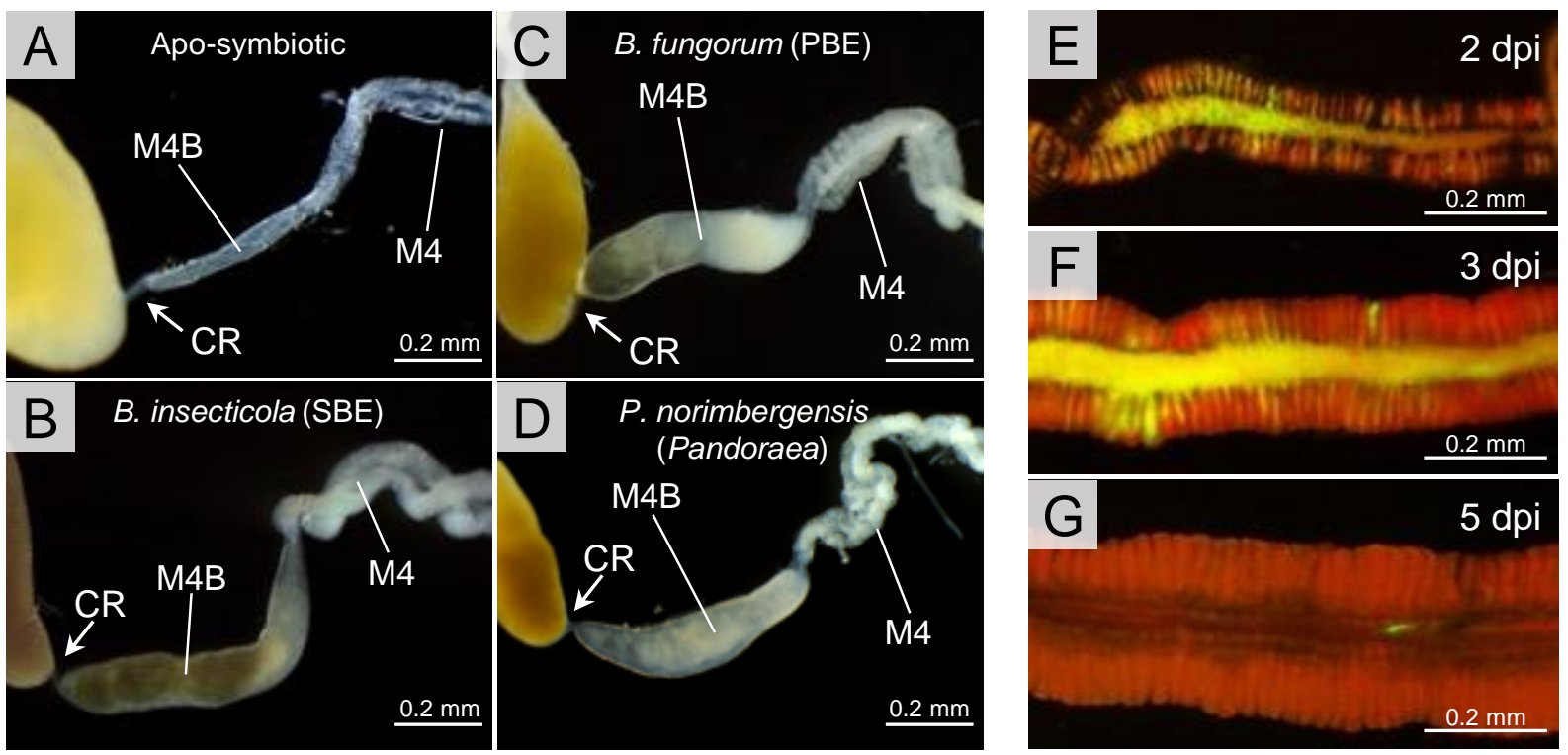

Red: SBE, Green: Pandoraea

$\mathrm{H}$

Early infection stage at the M4 ( 3 dpi)

Late infection stage at the M4 (5 dpi)
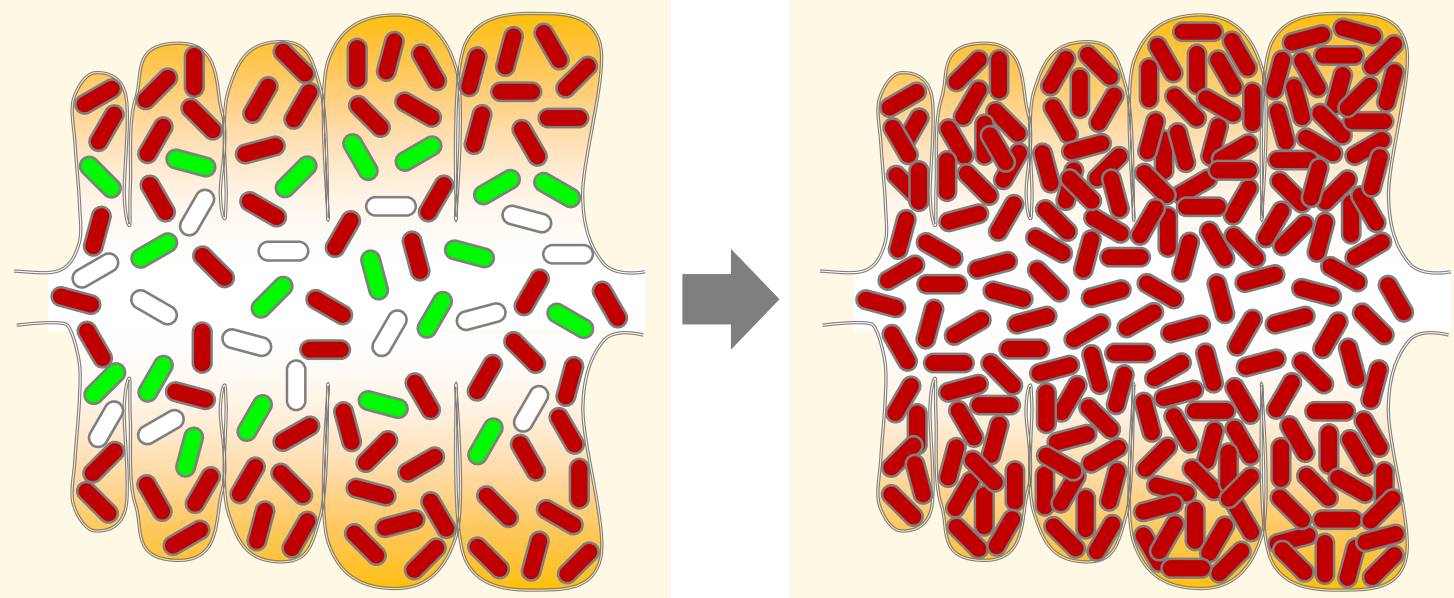

SBE $\quad \bigodot_{\text {PBE }}$ Pandoraea

